\title{
Management of Cerebral Brain Metastasis
}

\author{
Mira A. Patel $\cdot$ Jacob Ruzevick $\cdot$ Michael Lim
}

Published online: 17 October 2014

(C) Springer Science + Business Media New York 2014

\begin{abstract}
Brain metastasis is associated with a poor overall prognosis, but combination therapies have emerged that may prevent recurrence or serve as palliative therapies. There is a wide range of treatment options for those with 1-3 intracranial metastases and stable disease, including combinations of surgery, whole brain radiation therapy (WBRT), and stereotactic radiosurgery (SRS). Those with few, small metastases may be served well by SRS and adjuvant WBRT, whereas those with larger metastases that are amenable to resection may be treated with surgical excision and adjuvant WBRT. Whole brain radiation alone is reserved for individuals with greater than three brain metastases or unstable disease. A number of studies have been conducted to clarify the optimal treatment regimen for patients with varying intracranial disease. This review aims to synthesize the most current findings pertaining to the neurosurgical treatment of brain metastases.
\end{abstract}

Keywords Stereotactic radiosurgery - Brain metastasis . Whole brain radiation

This article is part of the Topical Collection on Brain Tumor Surgery.

M. A. Patel · J. Ruzevick · M. Lim $(\square)$

Department of Neurosurgery, The Johns Hopkins University

School of Medicine, 600 N Wolfe St., Phipps Building Rm 123,

Baltimore, MD 21287, USA

e-mail: mlim3@jhmi.edu

M. Lim

Department of Oncology, The Johns Hopkins University School of Medicine, Baltimore, MD 21287, USA

\section{Introduction}

If left untreated, brain metastases result in a median survival of 1 month, with mortality due largely to neurologic compromise [1]. Depending on a patient's functional status, disease burden, and histology, the major therapies for brain metastases include surgical excision, whole brain radiation therapy (WBRT), and stereotactic radiosurgery (SRS) [2]. Radiosensitive metastatic lesions include leukemia, lymphoma, small cell lung cancer, multiple myeloma, and germ cell tumors, whereas melanoma, renal cell carcinoma, and sarcoma are radioresistant; breast and nonsmall cell lung metastases lie somewhere in between [3]. The two primary goals of treatment are palliation or increasing recurrence-free survival.

To maximize treatment outcome and tailor therapy to individual patient needs, tools such as recursive partitioning analysis (RPA) and Karnofsky Performance Status (KPS) that describe patient characteristics have been developed. Based on the Radiation Therapy Oncology Group (RTOG) brain metastases trials, Gaspar and colleagues devised the RPA classification system which groups patients by age, KPS, and extracranial disease status. RPA Class 1 includes patients with KPS $\geq 70$ who are $<65$ years of age with no extracranial metastases and wellcontrolled primary disease; Class 3 includes those with KPS $<70$, and Class 2 includes all remaining patients [4]. Median OS is highest in Class 1 and progressively declines in Classes 2 and 3. A more recently devised classification system includes the Graded Prognostic Assessment (GPA), also based on the RTOG database, which follows three criteria: age, KPS, presence or absence of extracranial metastases, and number of brain metastases $[5,6 \bullet, 7]$. The disease-specific GPA assigns separate scores for the clinical criteria based on tumor type, which are then summed to 
Fig. 1 Treatment approach to intracranial metastases. WBRT whole brain radiation therapy; KPS karnofsky performance status; SRS stereotactic radiosurgery. Symptomatic lesion refers to intracranial symptomatology related to tumor mass effect. Note that the surgery + adjuvant WBRT approach relies more heavily on patient KPS and age, and there are no strict guidelines regarding this approach. The SRS + adjuvant WBRT approach may be used for 1-4 metastases for improved local tumor control

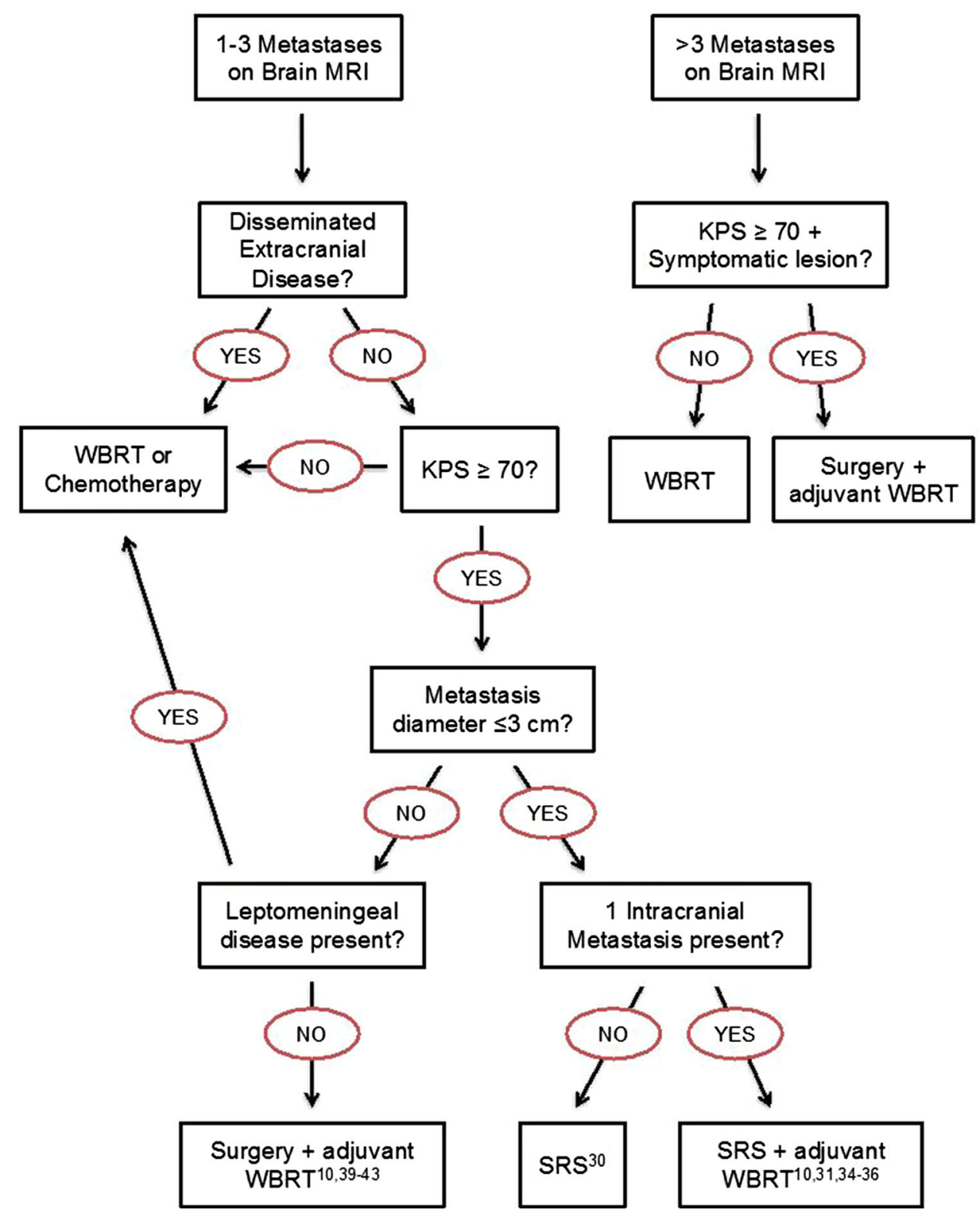

predict median overall survival (OS) [8]. These grading systems provide a basis for assigning appropriate treatment modalities that would best improve overall survival and/or local tumor control.

In 2013, the National Comprehensive Cancer Network updated their guidelines for the treatment of patients with brain metastases. In general, WBRT or chemotherapy is recommended for 1-3 brain metastases in patients who are not candidates for surgery due to disseminated non-CNS disease. In stable patients with good performance status and 1-3 brain metastases, surgery followed by WBRT and SRS, WBRT, or SRS alone is recommended. In patients with $>3$ brain metastases, WBRT alone is recommended $[3,9]$. With multiple treatment options available for newly diagnosed patients with 1-3 metastases with stable extracranial disease and good functional status, the treatment modality should be tailored to each individual patient. An algorithmic approach to the treatments summarized in the following discussion is outlined in Fig. 1.

\section{Whole Brain Radiation Therapy}

Prior to neurosurgical advances, WBRT was the standard treatment for brain metastases as it decreases the potential for metastatic dissemination in the brain and provides good local and regional tumor control [10•]. While WBRT had been the treatment of choice prior to improvements in neurosurgical technique and the development of SRS, today it is used largely as adjunctive therapy or as 
Table 1 Summary of randomized trials evaluating outcomes in varying WBRT dosing schedules

\begin{tabular}{|c|c|c|c|}
\hline First author & $\begin{array}{l}\text { Dose fractionation } \\
\text { scheme (Gy/fractions) }\end{array}$ & $\begin{array}{l}\text { Number } \\
\text { Treated }\end{array}$ & $\begin{array}{l}\text { Median OS } \\
\text { (months) }\end{array}$ \\
\hline \multirow{4}{*}{$\begin{array}{l}\text { Borgelt et al. [12] } \\
\text { (RTOG 6901) }\end{array}$} & $30 / 10$ & 233 & 4.8 \\
\hline & $30 / 15$ & 217 & 4.1 \\
\hline & $40 / 15$ & 233 & 4.1 \\
\hline & $40 / 20$ & 227 & 3.6 \\
\hline \multirow{3}{*}{$\begin{array}{l}\text { Borgelt et al. [12] } \\
\text { (RTOG 7361) }\end{array}$} & $20 / 5$ & 447 & 3.4 \\
\hline & $30 / 10$ & 228 & 3.6 \\
\hline & $40 / 15$ & 227 & 3.6 \\
\hline \multirow[t]{2}{*}{ Graham et al. [13] } & $40 / 20$ & 57 & 6.1 \\
\hline & $20 / 4$ & 56 & 6.6 \\
\hline \multirow[t]{2}{*}{ Murray et al. [14] } & $32 / 20$ & 216 & 4.5 \\
\hline & $30 / 10$ & 213 & 4.5 \\
\hline \multirow{2}{*}{$\begin{array}{l}\text { Priestman et al. } \\
\text { [15] }\end{array}$} & $30 / 10$ & 263 & 2.8 \\
\hline & $12 / 2$ & 270 & 2.5 \\
\hline \multirow[t]{2}{*}{ Phillips et al. [16] } & $37.5 / 15$ & 36 & 6.12 \\
\hline & $37.5 / 15+$ BrdUrd & 34 & 4.3 \\
\hline \multirow[t]{4}{*}{ Epstein et al. [17] } & $\begin{array}{l}32 / 20+48.0 \mathrm{~Gy} \\
\text { boost }\end{array}$ & 30 & 4.9 \\
\hline & $\begin{array}{l}32 / 20+54.4 \mathrm{~Gy} \\
\text { boost }\end{array}$ & 53 & 5.4 \\
\hline & $\begin{array}{l}32 / 20+64.0 \mathrm{~Gy} \\
\text { boost }\end{array}$ & 44 & 7.2 \\
\hline & $\begin{array}{l}32 / 20+70.4 \mathrm{~Gy} \\
\text { boost }\end{array}$ & 26 & 8.2 \\
\hline \multirow{2}{*}{$\begin{array}{l}\text { Haie-Meder et al. } \\
\text { [19] }\end{array}$} & $18 / 3$ & 110 & 4.2 \\
\hline & $\begin{array}{l}18 / 3+18 / 3(2 \\
\text { courses })\end{array}$ & 106 & 5.3 \\
\hline \multirow[t]{2}{*}{ Hoskin et al. [20] } & $35 / 15$ & 114 & 3.9 \\
\hline & $35 / 15+15 / 8$ boost & 50 & 4.7 \\
\hline \multirow[t]{2}{*}{ Kurtz et al. [21] } & $30 / 10$ & 130 & 4.55 \\
\hline & $50 / 20$ & 125 & 4.2 \\
\hline \multirow[t]{4}{*}{ Chatani et al. [22] } & 30/10, normal LDH & 46 & 5.4 \\
\hline & 50/20, normal LDH & 46 & 4.8 \\
\hline & 30/10, high LDH & 35 & 3.4 \\
\hline & 20/5, high LDH & 35 & 2.4 \\
\hline \multirow[t]{2}{*}{ Davey et al. [23] } & $40 / 20$ & 45 & 4.8 \\
\hline & $20 / 5$ & 45 & 4.8 \\
\hline \multirow[t]{4}{*}{$\begin{array}{l}\text { Komarnicky et al. } \\
\text { [24] }\end{array}$} & $\begin{array}{l}3 / 10+10 \mathrm{~g} / \mathrm{m}^{2} \\
\text { Misonidazole }\end{array}$ & 190 & 3.9 \\
\hline & $3 / 10$ & 193 & 4.5 \\
\hline & $\begin{array}{l}5 / 6+12 \mathrm{~g} / \mathrm{m}^{2} \\
\text { Misonidazole }\end{array}$ & 196 & 3.1 \\
\hline & $5 / 6$ & 200 & 4.1 \\
\hline
\end{tabular}

$p>.05$ between groups regarding median OS for all studies. BrdUrd bromodeoxyuridine $0.8 \mathrm{~g} / \mathrm{m}^{2}$ per day for 4 days of 3 weeks

monotherapy for metastases that are too numerous or are not amenable to surgery or SRS due to the patient's RPA status. WBRT alone is reserved for metastases that are not resectable or are unresponsive to radiation, but is recommended as a part of combination therapy with SRS or surgery in patients with stable disease. The standard dose of WBRT is $30 \mathrm{~Gy}$ in 10 fractions [3, 10•, 12-24] (Table 1). Median survival after WBRT is 3-6 months, with $10-15 \%$ of individuals surviving to 1 year [11]. Complete or partial tumor responses have been shown in $60 \%$ of recipients, and the tumor volume reduction resulting from WBRT leads to prolonged OS and better neurocognitive function preservation in the short term [11]. However, the Management of Brain Metastases Guidelines (MBMG) emphasize Gaspar and colleagues' findings that in those patients with 1-3 metastases and controlled extracranial disease, who are functionally independent (spend $<50 \%$ of time in bed); surgical resection followed by WBRT is the most appropriate therapy, as WBRT alone is insufficient in preventing disease progression [10•, 25]. There is not enough evidence to support surgery followed by WBRT in those with poor functional status and advanced systemic disease [25]. Although incompletely understood, the major risk of WBRT is neurocognitive. The neurocognitive decline associated with radiation can be subtle and poorly detected by routine MMSE [10•].

\section{Stereotactic Radiosurgery}

SRS involves directing multiple radiation beams from various angles at the target tumor volume, providing high dose radiation at the target while ensuring a rapid dose falloff to prevent destruction of adjacent tissues [26]. Brain metastases approximately $3 \mathrm{~cm}$ in diameter or less are ideal targets for SRS, owing to their spherical shape and relatively small size [10•]. Like surgery alone, SRS alone has shown little impact on extracranial metastasis control, though individual case reports have shown evidence of the abscopal effect, a phenomenon whereby localized irradiation to metastatic tumor causes shrinkage of tumor in sites far from the irradiated area [27-29]. Overall survival has also seen limited impact from SRS therapy $[3,11]$ Rades et al. [30] have reported that in RPA Class 1 and 2, SRS is more effective than WBRT alone regarding local tumor control, as measured by tumor size and recurrence. Chang and colleagues [33] report that in patients who receive WBRT in addition to SRS is at risk for neurocognitive decline, and they recommend SRS alone with salvage therapy to preserve quality of life. Patients report significant side affects associated with the addition of WBRT, including excess fatigue, memory loss, impaired concentration, and depression; as such, some physicians prefer upfront SRS as the primary radiotherapy and reserve WBRT for salvage therapy to minimize side effects and maintain quality of life [34]. Thus, regarding distant brain control 
Table 2 Summary of studies evaluating outcomes in combined modality therapies for brain metastasis

\begin{tabular}{|c|c|c|c|}
\hline First author & Treatment & $\begin{array}{l}\text { Number } \\
\text { treated }\end{array}$ & Outcome \\
\hline \multirow[t]{2}{*}{$\begin{array}{l}\text { Andrews et al. } \\
\text { [31] }\end{array}$} & WBRT + SRS & 167 & $\begin{array}{l}6.5 \\
\text { months }^{\mathrm{a}}\end{array}$ \\
\hline & WBRT alone & 164 & 4.9 months \\
\hline \multirow{2}{*}{$\begin{array}{l}\text { Aoyama et al. } \\
\text { [35] }\end{array}$} & WBRT + SRS & 57 & $41.5 \%^{\mathrm{b}}$ \\
\hline & SRS alone & 65 & $63.7 \%$ \\
\hline \multirow{2}{*}{$\begin{array}{l}\text { Patchell et al. } \\
\text { [39] }\end{array}$} & WBRT + Surgery & 25 & 9 months $^{\mathrm{a}}$ \\
\hline & WBRT alone & 23 & 3 months \\
\hline \multirow[t]{2}{*}{ Vecht et al. [40] } & WBRT + Surgery & 63 & $10^{\mathrm{a}}$ \\
\hline & WBRT alone & & 6 \\
\hline \multirow{3}{*}{$\begin{array}{l}\text { Patchell et al. } \\
\text { [42] }\end{array}$} & WBRT + Surgery & 49 & $18 \%^{\mathrm{c}}$ \\
\hline & Surgery alone & 46 & $70 \%$ \\
\hline & & & Median OS rate \\
\hline \multirow[t]{2}{*}{ Muacevic et al. [45] } & Surgery + WBRT & 52 & 53 \\
\hline & SRS & 56 & 43 \\
\hline \multirow[t]{3}{*}{ O'Neill et al. [46] } & Surgery & 74 & 62 \\
\hline & SRS & 23 & 56 \\
\hline & & & Median survival \\
\hline \multirow[t]{2}{*}{ Rades et al. [48] } & Surgery + WBRT & 52 & $47 \%^{d}$ \\
\hline & SRS + WBRT & 52 & $56 \%$ \\
\hline \multirow[t]{2}{*}{ Garell et al. [49] } & Surgery + WBRT & 37 & 8 months \\
\hline & SRS + WBRT & 8 & 12.5 months \\
\hline \multirow[t]{2}{*}{ Schoggl et al. [50] } & Surgery + WBRT & 66 & 9 months \\
\hline & $\mathrm{SRS}+\mathrm{WBRT}$ & 67 & 12 months \\
\hline
\end{tabular}

${ }^{a}$ Outcome measure is median survival

${ }^{b}$ Outcome measure is brain tumor recurrence rate at 1 year

c Outcome measure is rate of recurrence anywhere in the brain. OS overall survival

d 1 -year median survival rate. $p<.05$ for all outcomes listed

and median OS, the strength of SRS may lie in combined modality therapies, but its use alone with salvage therapy is more desirable overall when considering quality of life. Importantly, when used alone or as salvage therapy, SRS does not seem to compromise overall survival.

\section{Stereotactic Radiosurgery and Whole Brain Radiation Therapy}

Large randomized controlled trials have shown that in tumors $\leq 3 \mathrm{~cm}$ in size and exhibiting minimal mass effect, SRS added to WBRT provides local control rates of $60-75 \%$ at 2 years, distant brain control rates of $46 \%$ at 2 years, median OS of 10 months, a decreased need for steroids and a trend toward improved survival in RPA
Class 1 and 2 patients $[31,32]$. At least three randomized controlled studies have shown that the combination of SRS and WBRT has also proven to be an effective mode of therapy [31, 34-36]. Key studies are summarized in Table 2.

In a study of WBRT with or without SRS, Andrews et al. reported that in patients with single metastases, WBRT together with SRS significantly improved survival from 4.9 to 6.5 months $(p<.04)$ and improved the 3 -month response rate and local control at 1 year from 71 to $82 \%$ [31]. These results were corroborated by a number of other studies $[10 \bullet, 34,36]$. As a result, the current AANS/CNS guidelines report that single-dose SRS and added WBRT provide significantly longer patient survival compared to WBRT alone in patients with a single metastasis and KPS $\geq 70$. In addition, SRS and WBRT provide better local tumor control in those with 1-4 metastasis and KPS $\geq 70$ than WBRT alone [10•, 32, 34, 36]. Thus, WBRT and SRS together are a superior therapy in improving local control and OS in those with single metastasis compared to WBRT alone, and the addition of WBRT to SRS does not compromise overall survival.

Regarding SRS with or without WBRT, Aoyama and colleagues found statistically significant improvements in the SRS plus WBRT group versus SRS alone in the potential for developing new brain metastases at 1 year (41.5 vs. $63.7 \%, p=0.003$ ), in brain metastasis recurrence rate at 1 year $(46.8$ vs. $76.4 \%, p<.001)$, and in the local tumor control rate at 1 year (72.5 vs. $88.7 \%$, $p=.002$ ). In addition, they found no statistically significant change in neurotoxicity with the addition of WBRT [35]. However, as previously mentioned, in a study describing the outcomes of patients receiving either SRS or the combination of SRS and WBRT, Chang et al. [33] reported that those patients who received SRS and WBRT had worse neurocognitive function and OS. It should be noted that others have indicated a number of issues with this study that may compromise the validity of its findings, including problems with appropriate balance of study groups and assessment of neurocognitive function [3].

\section{Surgery}

The purpose of surgical resection of brain metastases is to provide tissue diagnosis, local tumor control, and alleviation of symptoms emerging from mass effect or hydrocephalus caused by the tumor without causing further neurologic deficit [32]. Prior to resection, it is important to identify the size, number, and location of lesions as all can impact the decision to proceed. Lesions smaller than $0.5 \mathrm{~cm}$ are generally considered too small to warrant surgery, whereas those $>3 \mathrm{~cm}$ generally cause more 
worrisome clinical manifestations as a result of tumor mass effect, such as cognitive decline and gait problems. Surgery is usually advisable only for a single lesion or approximately three or fewer large lesions that can be removed in a single craniotomy, although the surgeon's clinical judgment is the primary guide to the upper limit of the number of lesions removed in a craniotomy. Additionally, the tumor must be accessible surgically without damaging adjacent eloquent structures [10•]. Since the 1980s, surgery has been strongly indicated for the treatment of single metastases in patients with stable or controlled extracranial disease and good functional status [11, 37]. In those with $>3$ metastases or with concomitant intraparenchymal or leptomeningeal disease, surgery is contraindicated, but the role of surgery is less clear in patients with 2-3 metastases and is largely left to the surgeon's discretion [37]. It is important to note that surgery can be used in situations that improve quality of life; for example, in a patient with $>3$ metastases with excellent performance status, who suffers from hydrocephalus due to a large cerebellar metastasis. Evidence shows that piecemeal resection of a posterior fossa mass is more likely to cause leptomeningeal disease than en bloc surgical resection; in other words, surgical technique can impact postoperative quality of life [38]. Furthermore, it is important to note that surgery is a therapy tailored to patient characteristics, such as KPS and age- there are no stringent surgical guidelines based on number of metastases alone. Advances in technology and surgical technique have made surgery a very safe option with rapid recovery time, with the downside being that chemotherapy must be delayed for at least 2-3 weeks after surgery in order to enable wound healing.

\section{Surgery and WBRT}

Three randomized controlled trials have studied the difference between WBRT with and without surgery [39-41]. Patchell et al. [39] showed that surgery followed by WBRT significantly improves median OS ( 9 vs. 3 months), decreases local recurrence (20 vs. $52 \%$ ), decreases "neurologic death" (14 vs. 6 months), and increases time to recurrence ( $>14$ vs. 5 months) compared to WBRT alone. Vecht and colleagues [40] corroborated these results, showing an improvement in median OS those who received surgery plus WBRT versus WBRT alone (10 vs. 6 months, $p<.05$ ), specifically in those with stable extracranial disease, with no improvement in median OS in those with progressive systemic disease. Those with stable extracranial disease also had longer functional independence with surgery plus WBRT (4 vs. 9 months) than those with progressive extracranial disease (2.5 months for both treatments). Mintz and colleagues [41] produced the only study that failed to show an improvement in median OS in those who received surgery plus WBRT, but this may be attributable to the enrollment of those with worse baseline KPS - a population that has been shown to derive little benefit from the addition of surgery to WBRT [3].

Regarding the difference between surgery with or without WBRT, there has been one randomized clinical trial revealing that the addition of WBRT decreases neurologic death (14 vs. $44 \%, p<.05)$, and is associated with less recurrence at the site of resection (10 vs. $46 \%$, $p<.05)$ and at distant sites in the brain (14 vs. $37 \%$, $p<.05$ ) [42]. This study did not show a significant improvement in median OS, but the recurrence in surgery plus WBRT was significantly decreased compared to surgery alone (18 vs. $70 \%, p<.001)$. The evidence-based Management of Brian Metastasis Guidelines (MBMG) emphasize that surgery followed by WBRT improves tumor control at the original tumor site as well as in the brain overall and that even those with uncontrolled systemic disease with KPS $\geq 70$ can benefit from such local control $\left[10^{\bullet}, 43\right]$. Thus, in the absence of disseminated disease, surgery plus WBRT reduces the risk of recurrence, likely by eliminating micrometastases in the brain and microscopic disease in the tumor bed [37]. Key studies in this section are summarized in Table 2.

\section{Surgery and Stereotactic Radiosurgery}

While there have been no randomized clinical trials comparing surgery plus SRS or surgery versus SRS, retrospective analyses have shown similar survival improvement between SRS and surgery alone, and the decision to perform surgery or SRS should be made on a case-by-case basis, accounting for symptomaticity, tumor site, size, and surgeon's preference [11,44-46]. O'Neill and colleagues have shown that SRS is more effective at preventing local recurrences $(0 \%, 0 / 26)$ than surgery (27\%, 19/74). 46 In terms of surgery and SRS used together, a retrospective study has shown that giving a local boost of SRS into the surgical tumor bed has been shown to confer excellent survival and local control rates comparable to WBRT, sparing the patient the neurologic side effects of WBRT [47]. While SRS has been shown to be just as effective as surgery regarding survival, the inherent limitations of the retrospective analyses preclude the establishment of standard guidelines when comparing the two modalities; clearly, data from clinical trials can help resolve any controversy. A brief summary of major retrospective studies regarding SRS versus surgery is shown in Table 2. 


\section{Other Combinations}

Regarding the effectiveness SRS plus WBRT versus surgery plus WBRT based on retrospective studies, the MBMG recommended with clinical certainty that both combinations are equally as effective and result in equal survival rates [10॰, 48-50]. Rades and colleagues [48] concluded through retrospective analysis that SRS + WBRT is at least as effective as surgery + WBRT for the treatment of 1-3 brain metastases. They report $56 \%$ 1-year OS after SRS + WBRT and $47 \%$ after surgery + WBRT $(p=.034), 82$ and $66 \% 1$-year local control $(p=.006)$, and 66 and $50 \%$ intracerebral tumor control at 1 year $(p=.003)$ for SRS + WBRT and surgery + WBRT, respectively. Similarly, Garell et al. report no significant difference in median survival between surgery + WBRT (8 months) and SRS + WBRT (12.5 months), and Schoggl et al. confirm these results (surgery + WBRT, 9 months; SRS + WBRT, 12 months; $p>.05)[49,50]$. Nevertheless, as mentioned previously, lesions $<3 \mathrm{~cm}$ in diameter that are surgically inaccessible are more amenable to SRS, whereas lesions $>3 \mathrm{~cm}$ and resulting in $>1 \mathrm{~cm}$ of midline shift may have better outcomes if surgically removed $\left[10^{\bullet}, 43\right]$. A brief summary of available studies is shown in Table 2.

\section{Conclusions}

A number of treatment modalities are available to those with brain metastasis, as outlined in Fig. 1. While those with disseminated or advanced disease should likely receive WBRT, those who have intracranial disease limited to 1-3 metastases and have otherwise positive performance status may receive therapy tailored to their disease presentation. Metastases smaller than or equal to $3 \mathrm{~cm}$ in diameter may be well controlled by SRS and adjuvant WBRT, as studies have demonstrated decreased local recurrence, whereas larger and symptomatic metastases may be amenable to en bloc surgical resection. Given the variety of treatment options available to those with stable brain metastasis, it is important to tailor therapy to each patient's disease and ability to tolerate the procedure.

\section{Compliance with Ethics Guidelines}

Conflict of Interest Mira A. Patel and Jacob Ruzevick declare no conflict of interest. Michael Lim reports Grants and personal fees from Accuray.

Human and Animal Rights and Informed Consent This article does not contain any studies with human or animal subjects performed by the authors.

\section{References}

Papers of particular interest, published recently, have been highlighted as:

- Of importance

1. Patchell RA. The management of brain metastases. Cancer Treat Rev. 2003;29(6):533-40.

2. Kellner CP, D'Ambrosio AL. Surgical management of brain metastases. Neurosurg Clin N Am. 2011;22(1):53-9 vi.

3. Den R, Andrews DW. Radiotherapy for brain metastases. Neurosurg Clin N Am. 2011;22(1):37-44.

4. Gaspar L, Scott C, Rotman M, et al. Recursive partitioning analysis (RPA) of prognostic factors in three radiation therapy oncology group (RTOG) brain metastases trials. Int J Radiat Oncol Biol Phys. 1997;37(4):745-51.

5. Sperduto CM, Watanabe Y, Mullan J, et al. A validation study of a new prognostic index for patients with brain metastases: the graded prognostic assessment. J Neurosurg. 2008;109(Suppl): 87-9.

6. - Villa S, Weber DC, Moretones C, et al. Validation of the new graded prognostic assessment scale for brain metastases: A multicenter prospective study. Radiat Oncol. 2011;6:23. This study validates the Graded Prognostic Assessment as a novel prognostic tool for the assessment of metastatic brain cancer based on tumor sub-type and patient age and performance status. It is the first such tool to stratify patients with brain metastasis based on tumor sub-type.

7. Sperduto PW, Berkey B, Gaspar LE, Mehta M, Curran W. A new prognostic index and comparison to three other indices for patients with brain metastases: an analysis of 1,960 patients in the RTOG database. Int J Radiat Oncol Biol Phys. 2008;70(2):510-4.

8. Sperduto PW, Chao ST, Sneed PK, et al. Diagnosis-specific prognostic factors, indexes, and treatment outcomes for patients with newly diagnosed brain metastases: a multi-institutional analysis of 4,259 patients. Int J Radiat Oncol Biol Phys. 2010;77(3):655-61.

9. National Comprehensive Cancer Network. NCCN clinical practice guidelines in oncology: Central nervous system cancers. 2013; Version 2.2013.

10. • Bhangoo SS, Linskey ME, Kalkanis SN, American Association of Neurologic Surgeons (AANS), Congress of Neurologic Surgeons (CNS). Evidence-based guidelines for the management of brain metastases. Neurosurg Clin N Am. 2011;22(1):97-104, viii. This report is a concise and evidence-based summary of relevant approaches to brain metastasis.

11. Soffietti R, Ruda R, Trevisan E. Brain metastases: current management and new developments. Curr Opin Oncol. 2008;20(6): 676-84.

12. Borgelt B, Gelber R, Kramer S, et al. The palliation of brain metastases: final results of the first two studies by the radiation therapy oncology group. Int $\mathbf{J}$ Radiat Oncol Biol Phys. 1980;6(1):1-9.

13. Graham P, Bucci J, Browne L. Randomized comparison of whole brain radiotherapy, 20 gy in four daily fractions versus 40 gy in 20 twice-daily fractions, for brain metastases. Int J Radiat Oncol Biol Phys. 2010;77(3):648-54.

14. Murray KJ, Scott C, Greenberg HM, et al. A randomized phase III study of accelerated hyperfractionation versus standard in patients with unresected brain metastases: a report of the radiation therapy oncology group (RTOG) 9104. Int J Radiat Oncol Biol Phys. 1997;39(3):571-4. 
15. Priestman T, Dunn J, Brada M, Rampling R, Baker P. Final results of the royal college of radiologists' trial comparing two different radiotherapy schedules in the treatment of cerebral metastases. Clin Oncol. 1996;8(5):308-15.

16. Phillips TL, Scott CB, Leibel SA, Rotman M, Weigensberg IJ. Results of a randomized comparison of radiotherapy and bromodeoxyuridine with radiotherapy alone for brain metastases: report of RTOG trial 89-05. Int J Radiat Oncol Biol Phys. 1995;33(2):339-48.

17. Epstein BE, Scott CB, Sause WT, et al. Improved survival duration in patients with unresected solitary brain metastasis using accelerated hyperfractionated radiation therapy at total doses of 54.4 gray and greater results of radiation therapy oncology group 85-28. Cancer. 1993;71(4):1362-7.

18. Sause WT, Scott C, Krisch R, et al. Phase I/II trial of accelerated fractionation in brain metastases RTOG 85-28. Int J Radiat Oncol Biol Phys. 1993;26(4):653-7.

19. Haie-Meder C, Pellae-Cosset B, Laplanche A, et al. Results of a randomized clinical trial comparing two radiation schedules in the palliative treatment of brain metastases. Radiother Oncol. 1993;26(2):111-6.

20. Hoskin P, Crow J, Ford $\mathrm{H}$. The influence of extent and local management on the outcome of radiotherapy for brain metastases. Int J Radiat Oncol Biol Phys. 1990;19(1):111-5.

21. Kurtz JM, Gelber R, Brady LW, Carella RJ, Cooper JS. The palliation of brain metastases in a favorable patient population: a randomized clinical trial by the radiation therapy oncology group. Int J Radiat Oncol Biol Phys. 1981;7(7):891-5.

22. Chatani M, Matayoshi Y, Masaki N, Inoue T. Radiation therapy for brain metastases from lung carcinoma. prospective randomized trial according to the level of lactate dehydrogenase. Strahlenther Onkol. 1994;170(3):155-61.

23. Davey P, Hoegler D, Ennis M, Smith J. A phase III study of accelerated versus conventional hypofractionated whole brain irradiation in patients of good performance status with brain metastases not suitable for surgical excision. Radiother Oncol. 2008;88(2):173-6.

24. Komarnicky LT, Phillips TL, Martz K, Asbell S, Isaacson S, Urtasun R. A randomized phase III protocol for the evaluation of misonidazole combined with radiation in the treatment of patients with brain metastases (RTOG-7916). Int J Radiat Oncol Biol Phys. 1991;20(1):53-8.

25. Gaspar LE, Mehta MP, Patchell RA, et al. The role of whole brain radiation therapy in the management of newly diagnosed brain metastases: a systematic review and evidence-based clinical practice guideline. J Neurooncol. 2010;96(1):17-32.

26. D'Ambrosio AL, DeYoung C, Isaacson SR. Radiosurgical management of brain metastases. Neurosurg Clin N Am. 2011;22(1): 45-51 vi.

27. Kingsley D. An interesting case of possible abscopal effect in malignant melanoma. Br J Radiol. 1975;48(574):863-6.

28. Stamell EF, Wolchok JD, Gnjatic S, Lee NY, Brownell I. The abscopal effect associated with a systemic anti-melanoma immune response. Int J Radiat Oncol Biol Phys. 2013;85(2):293-5.

29. Hiniker SM, Chen DS, Knox SJ. Abscopal effect in a patient with melanoma. N Engl J Med. 2012;366(2035):2035-6.

30. Rades D, Pluemer A, Veninga T, Hanssens P, Dunst J, Schild SE. Whole-brain radiotherapy versus stereotactic radiosurgery for patients in recursive partitioning analysis classes 1 and 2 with 1 to 3 brain metastases. Cancer. 2007;110(10):2285-92.

31. Andrews DW, Scott CB, Sperduto PW, et al. Whole brain radiation therapy with or without stereotactic radiosurgery boost for patients with one to three brain metastases: phase III results of the RTOG 9508 randomised trial. The Lancet. 2004;363(9422):1665.

32. Butowski N. Medical management of brain metastases. Neurosurg Clin. 2011;22(1):27.
33. Chang EL, Wefel JS, Hess KR, et al. Neurocognition in patients with brain metastases treated with radiosurgery or radiosurgery plus whole-brain irradiation: a randomised controlled trial. Lancet Oncol. 2009;10(11):1037-44.

34. Kondziolka D, Patel A, Lunsford LD, Kassam A, Flickinger JC. Stereotactic radiosurgery plus whole brain radiotherapy versus radiotherapy alone for patients with multiple brain metastases. Int J Radiat Oncol Biol Phys. 1999;45(2):427.

35. Aoyama $\mathrm{H}$, Shirato $\mathrm{H}$, Tago M, et al. Stereotactic radiosurgery plus whole-brain radiation therapy vs stereotactic radiosurgery alone for treatment of brain metastases. JAMA. 2006;295(21):2483-91.

36. Linskey ME, Andrews DW, Asher AL, et al. The role of stereotactic radiosurgery in the management of patients with newly diagnosed brain metastases: a systematic review and evidencebased clinical practice guideline. J Neurooncol. 2010;96(1):45-68.

37. Modha A, Shepard SR, Gutin PH. Surgery of brain metastases-Is there still a place for it? J Neurooncol. 2005;75(1):21-9.

38. Suki D, Abouassi H, Patel AJ, Sawaya R, Weinberg JS, Groves MD. Comparative risk of leptomeningeal disease after resection or stereotactic radiosurgery for solid tumor metastasis to the posterior fossa. J Neurosurg. 2008;108(2):248-57.

39. Patchell RA, Tibbs PA, Walsh JW, et al. A randomized trial of surgery in the treatment of single metastases to the brain. N Engl J Med. 1990;322(8):494-500.

40. Vecht CJ, Haaxma-Reiche H, Noordijk EM, et al. Treatment of single brain metastasis: radiotherapy alone or combined with neurosurgery. Ann Neurol. 1993;33(6):583-90.

41. Mintz AH, Kestle J, Rathbone MP, et al. A randomized trial to assess the efficacy of surgery in addition to radiotherapy in patients with a single cerebral metastasis. Cancer. 1996;78(7):1470-6.

42. Patchell RA, Tibbs PA, Regine WF, et al. Postoperative radiotherapy in the treatment of single metastases to the brain. JAMA. 1998;280(17):1485-9.

43. Kalkanis SN, Kondziolka D, Gaspar LE, et al. The role of surgical resection in the management of newly diagnosed brain metastases: a systematic review and evidence-based clinical practice guideline. J Neurooncol. 2010;96(1):33-43.

44. Auchter RM, Lamond JP, Alexander E III, et al. A multiinstitutional outcome and prognostic factor analysis of radiosurgery for resectable single brain metastasis. Int J Radiat Oncol Biol Phys. 1996;35(1):27-35.

45. Muacevic A, Kreth FW, Horstmann GA, et al. Surgery and radiotherapy compared with gamma knife radiosurgery in the treatment of solitary single cerebral metastases of small diameter. J Neurosurg. 1999;91(1):35-43.

46. O’Neill BP, Iturria NJ, Link MJ, Pollock BE, Ballman KV, O'Fallon JR. A comparison of surgical resection and stereotactic radiosurgery in the treatment of solitary brain metastases. Int $\mathrm{J}$ Radiat Oncol Biol Phys. 2003;55(5):1169-76.

47. Quigley MR, Fuhrer R, Karlovits S, Karlovits B, Johnson M. Single session stereotactic radiosurgery boost to the post-operative site in lieu of whole brain radiation in metastatic brain disease. J Neurooncol. 2008;87(3):327-32.

48. Rades D, Kueter J, Veninga T, Gliemroth J, Schild SE. Whole brain radiotherapy plus stereotactic radiosurgery (WBRT SRS) versus surgery plus whole brain radiotherapy (OP WBRT) for 1-3 brain metastases: results of a matched pair analysis. Eur $\mathbf{J}$ Cancer. 2009;45(3):400-4.

49. Garell PC, Hitchon PW, Wen BC, Mellenberg DE, Torner J. Stereotactic radiosurgery versus microsurgical resection for the initial treatment of metastatic cancer to the brain. J Radiosurgery. 1999;2(1):1-5.

50. Schöggl A, Kitz K, Reddy M, Schneider B, Dieckmann K, Ungersböck K. Defining the role of stereotactic radiosurgery versus microsurgery in the treatment of single brain metastases. Acta Neurochir. 2000;142(6):621-6. 